\title{
Physical Comorbidity and Psychiatric Diagnosis in a Neuropsychiatric Clinic in Sindhuli District, Rural Nepal
}

\author{
Belbase $\mathbf{M}^{1}$, Joshi $\mathrm{D}^{2}$, Boki $\mathrm{A}^{3}$, Gautam $\mathrm{R}^{4}$, Sharma $\mathrm{R}^{5}$, Adhikari $\mathrm{J}^{6}$ \\ 1.Psychiatrist, Tranquility Hospital and Research Centre(THRC), Khumaltar, Lalitpur, Nepal 2. Psychiatrist, \\ THRC, Lalitpur, Nepal 3. Chief Administrator, THRC, Lalitpur 4. Administrative Officer, THRC, Lalitpur \\ 5.Clinical Psychologist, THRC, Lalitpur 6.Resident, Department of paediatrics, NGMCTH, Kohalpur, Nepal
}

Email *Corresponding author: mohanbelbase@yahoo.com

\begin{abstract}
Background: Presence of physical illness with mental health problems is very common occurrence. Contraindication of certain psychotropics with certain physical problem and some beneficial effects of other drugs in comorbid conditions is one of important aspect of studying comorbidity. Comorbidity identification and intervention helps to cure and contain mental problems in most effective way.
\end{abstract}

Materials and methods: Descriptive study with convenient sampling in all the patients who consented and attended monthly neuropsychiatric satellite health camp in Sindhuli district of Nepal from the month of Shrawan to Poush 2069 (6 months) organized by Tranquility Hospital and Research Centre, Khumaltar, Kathamndu.

Results: Out of the 172 subjects studied, the most common age group was 20-39 years (47.7\%) followed by 40-59 years $(27.9 \%)$.

The most common neuropsychiatric diagnosis was mood spectrum disorder followed by neurotic (neurotic, stressrelated and somatoform) disorders. Psychosis spectrum (schizophrenia, schizotypal and delusional disorders) was the least common.

The most common physical comorbid diagnosis was migraine followed by hypertension and diabetes mellitus.

Conclusions: Migraine, hypertension and diabetes mellitus are the most common comorbid physical problems in psychiatric population found in our study.

Keywords: Physical comorbidity, Psychiatry disorders, Rural Nepal

\section{INTRODUCTION}

Presence of physical illness with mental health disorder is very common occurrence. This physical comorbidity in mental health disorder complicates the patient's condition making the management part further challenging to both the doctor and the patient. Contraindication of certain psychotropics with certain physical problem and some beneficial effects of other drugs in comorbid conditions is one of important aspect of studying comorbidity. There is a unity of mind and body (reflected in the term mind-body medicine); and psychological factors must be taken into account when considering all disease states. ${ }^{1}$

As the causes of mental problems are explained on the basis of bio-psycho-social model, the role of stressors is very important in its etiology. Sometimes presence of some physical illness can cause significant stress making the person vulnerable for the mental illness. Similarly, 
mental illness also can make patients vulnerable to have physical illness as some 75 percent of physical disease are said to be stress related. ${ }^{2}$

Depression and eating disorders (in women) are more common in individuals with type 1 or type 2 diabetes mellitus. ${ }^{3}$

Schizophrenia is associated with an increased risk of type 2 diabetes mellitus, obesity, increased rate of smoking, diabetes, hyperlipidemia and sedentary lifestyle, all independently increasing the risk of cardiovascular morbidity and mortality. ${ }^{4}$

Similarly migraine can present with multifaceted symptoms emanating from multiple systems, including vascular, neurological, gastrointestinal, endocrine and visual. These symptoms may be accompanied by a variety of change in behavior and cognition, including mood alterations and confusion. Comorbid psychiatric disorders such as depression, particularly bipolar subtype, and phobia and panic states have been reported in migraine. ${ }^{4}$

Comorbidity of physical illness is a very common phenomenon with mental disorders but there is lack of such studies in our country. As comorbidity identification and intervention helps to cure and contain mental problems in most effective way, the study is carried out to understand the physical comorbidity with mental disorders in rural areas of eastern Nepal.

\section{MATERIALS AND METHOD}

This is a descriptive study with convenient sampling in the patients attending monthly neuropsychiatric satellite health camp in Sindhuli district of Nepal. The sample include all the patients attending the camp from the month of Shrawan to Poush 2069 (6 months) organized by Tranquility Hospital and Research Centre, Khumaltar. Altogether 172 patients who consented were included in the study and their demographic variables were recorded by a psychiatrist. Psychiatric diagnosis was made using ICD-10 (International Statistical
Classification of Diseases and Related Health Problems 10th Revision). ${ }^{5}$

Diagnosis of hypertension, diabetes mellitus and migraine was made by the same psychiatrist on the basis of the criteria given in the Harrison's Principles of Internal Medicine. ${ }^{3}$

For hypertension, blood pressure was measured and patients falling above the cut off value of 140/90 mmhg were included. For diabetes mellitus, blood sugar was sent to the clinic's laboratory and the patients having symptoms of diabetes with random blood glucose $>11.1$ $\mathrm{mmol} / \mathrm{l}(200 \mathrm{mg} / \mathrm{dl})$ or fasting blood glucose $>$ $7.0 \mathrm{mmol} / 1$ (126 mg/dl) were included.

Diagnosis of migraine was done by the psychiatrist using the diagnostic criteria given by the International Headache Society (http://www.ihs-headache.org/) during the clinical interview.

Data were analyzed using SPSS (Version 11.5) and presented in tables.

\section{RESULTS}

Total number of 172 patients were studied of which 94 were male while 78 were female. The most common age group is $20-39$ years $(47.7 \%)$ followed by $40-59$ years (27.9 \%).

The most common neuropsychiatric diagnosis spectrum was mood disorder followed by neurotic (neurotic, stress-related and somatoform) disorder. Psychosis spectrum (schizophrenia, schizotypal and delusional disorders) was the least common.

Regarding the comorbidity, migraine was the most common single comorbid diagnosis followed by hypertension and diabetes mellitus. All the findings are tabulated below.

Table 1. Age and Gender Distributions.

\begin{tabular}{|l|l|l|l|l|}
\hline \multirow{2}{*}{$\begin{array}{l}\text { Age in } \\
\text { years }\end{array}$} & \multicolumn{2}{|l|}{ Gender } & \multicolumn{2}{l|}{ Total no of patients } \\
\cline { 2 - 5 } & M & F & No & Percentage \\
\hline$<19$ & 8 & 12 & 20 & 11.6 \\
\hline $20-39$ & 42 & 40 & 82 & 47.7 \\
\hline $40-59$ & 28 & 20 & 48 & 27.9 \\
\hline$>60$ & 16 & 6 & 22 & 12.8 \\
\hline Total & 94 & 78 & 172 & 100 \\
\hline
\end{tabular}


Table 2. ICD-10 Spectrum Diagnosis with Age Range.

\begin{tabular}{|l|l|l|l|l|l|l|l|l|}
\hline \multirow{2}{*}{$\begin{array}{l}\text { Age in } \\
\text { years }\end{array}$} & \multicolumn{9}{|c|}{ ICD-10 Spectrum Diagnosis } \\
\cline { 2 - 9 } & Psychosis & \multicolumn{2}{|l|}{ Mood } & Neurotic & \multicolumn{2}{l|}{ Others } \\
\cline { 2 - 9 } & No & Percentage & No & Percentage & No & Percentage & No & Percentage \\
\hline$<19$ & 2 & 1.2 & 10 & 5.9 & 8 & 4.6 & 2 & 1.2 \\
\hline $20-39$ & 6 & 3.5 & 36 & 21.0 & 24 & 14.0 & 24 & 14.0 \\
\hline $40-59$ & 8 & 4.6 & 16 & 9.3 & 24 & 14.0 & 6 & 3.5 \\
\hline$>60$ & - & - & 12 & 7.0 & 8 & 4.6 & 2 & 1.2 \\
\hline Total & 16 & 9.3 & 74 & 43.2 & 64 & 37.2 & 34 & 19.9 \\
\hline
\end{tabular}

Table 3. Physical comorbidity with respect to age range.

\begin{tabular}{|c|c|c|c|c|c|c|c|c|}
\hline \multirow{3}{*}{$\begin{array}{l}\text { Age in } \\
\text { Years }\end{array}$} & \multicolumn{8}{|c|}{ Physical comorbidity } \\
\hline & \multicolumn{2}{|c|}{ Hypertension } & \multicolumn{2}{|c|}{ Diabetes } & \multicolumn{2}{|c|}{ Migraine } & \multicolumn{2}{|c|}{ Others } \\
\hline & No & Percentage & No & Percentage & No & Percentage & No & Percentage \\
\hline$<19$ & - & - & - & - & 3 & 1.7 & 1 & 0.5 \\
\hline 20-39 & 2 & 1.2 & 1 & 0.5 & 11 & 6.3 & 4 & 2.4 \\
\hline $40-59$ & 3 & 1.7 & 2 & 1.2 & 3 & 1.7 & 2 & 1.2 \\
\hline$>60$ & 8 & 4.6 & 3 & 1.7 & - & - & 8 & 4.6 \\
\hline Total & 13 & 7.5 & 6 & 3.4 & 17 & 9.7 & 15 & 8.7 \\
\hline
\end{tabular}

\section{DISCUSSIONS}

Our study reveals that in rural mental health clinic in Nepal the most common

Neuropsychiatric diagnosis was mood spectrum disorders 74(43\%) followed by neurosis 64(37\%) with least being the psychosis spectrum $16(9 \%)$. Mood disorder was most common in 20-39 years representing $21 \%$ of total followed by neurosis which was equally common in 20-39 years and 40-59 years representing $14 \%$ each. The high prevalence of mood disorders and neurosis in 20-59 age groups, in our study, is in accordance to standard textbooks. ${ }^{1,6}$

Psychosis spectrum was found to be highest in 40-59 years representing $4.6 \%$ of the total which was unusual, considering the fact that psychosis is said to be common in younger age. This could be due to small sample size and the reflection of spectrum rather than single psychotic entity used in this study.

The most common physical comorbidity in the people suffering from mental disorders was migraine representing about $10 \%$ of the study population. It could be due to truly high prevalence of migraine and/or selection biases as the psychiatrist in Nepal are main treatment provider for headaches.

Hypertension was present in $13(7.5 \%)$ cases and was most common in 60 years and older. More than one third (8 out of 22) of 60 years and older had hypertension which could be due to surge in hypertension prevalence with progressive age. 7 This finding is similar to the findings of the study done in Lucknow where the prevalence of hypertension in psychiatry disorder was 7.1 percent with increase in frequency with their progressive age. Based on the age group, the prevalence was $1.48 \%$ in 20-39 years, $24.4 \%$ in 40-60 years and $33.3 \%$ in older than 60 years group. ${ }^{8}$

Diabetes was also most common in the 60 years and older which could be due to progressive age being the time of onset of type 2 diabetes mellitus. 
Though individually not analyzed and no correlation being done in our study due to small sample size, one study in Australia reported that of the main group of mental disorders, the highest rate of comorbidity with a physical condition is seen for anxiety disorders. ${ }^{9}$

Even though the exact nature of mental and physical disorder is not clear most of the times, some have suggested it to be bidirectional creating an interface between various medical specialties. Cardiovascular disease, hypertension, respiratory disorders, diabetes mellitus and other metabolic disorders seem to be associated with mental disorders. Various factors such as unhealthy lifestyle, habits, psychotropic medication, and inadequate medical treatment or provision are implicated. ${ }^{10}$

Small sample size, non randomized sample and being unable to study individual psychiatric disorders and its relationship with the physical comorbidity are the limitations of this study.

\section{CONCLUSIONS}

Migraine, hypertension and diabetes mellitus are the most common comorbid physical problems in psychiatric population found in our study. Larger and more systemic studies are needed to explore these findings further. Our findings suggest that every psychiatrist should look for comorbid physical problems in our daily practice.

\section{CONFLICT OF INTEREST- No}

FUNDING- None

\section{REFERENCES}

1. Sadok BJ, Sadok VA. Kaplan \& Sadock's synopsis of psychiatry Behavioral Science/Clinical Psychiatry. 10th ed. New Delhi: Wolters Kluwer (India) Pvt. Ltd.; 2007. P. 529,622,813.

2. Morgan CT, King RA, Weisz JR, Schopler J. Introduction to Psychology. 7th ed. New Delhi: Tata McGra-Hill Publishing Company Limited 2005. P. 321.

3. Braunwald E, Fauci AS, Kasper DL, Hauser SL, Longo DL, Jameson JL. Harrison's Principles of Internal
Medicine. 15th ed. United Statets: McGraw- Hill; 2001. P. 2135

4. Sadock BJ, Sadock VA. Kaplan \& Sadock's Comprehensive Textbook of Psychiatry. 8th ed. Philadelphia, USA: Lippincott Williams \& Wilkins; 2005. P. 481-83,1435,485

5. World Health Organization Geneva. The ICD-10 Classification of Mental and Behavioural Disorders, clinical descriptions and diagnostic guidelines. Delhi: A.I.T.B.S. Publishers and Distributors; 2002

6. Gelder M, Harrison P, Cowen P. Shorter Oxford Textbook of psychiatry. 5th ed. New York: Oxford University Press; 2006. P.230.

7. Park K. Park's Textbook of preventive and Social Medicine. 22nd ed. Premnagar,Jabalpur, India: M/s Banarsidas Bhanot; 2009. P. 325

8. Vaish AK, Kumar H, Agrawal CG, Chandra M, trivedi JK, Gatak A, et al. prevalence of hypertension in psychiatric disorders. J Assoc Physicians India. 2002 Jun [ cited 2013 May 15]; 50:800-2: [3]. Available from: http://www.ncbi.nlm.nih.gov/pubmed / 12240846

9. Australian Institute of Health and Welfare. Comorbidity of mental disorders and physical conditions 2007. Cat. No PHE 155. Canberra: AIHW [ cited 2013 Apr 9]. Available from www.aihw.gov.au

10. Iacovidas A, Siamauli M. Comorbid mental and somatic disorders: an epidemiological prospective. $2008 \mathrm{Jul}$ [cited 2013 Apr 7]; 21(4):417-21. [doi: 10.1097/YCO.Ob013e328303ba42]. Available from: www.ncbi.hlm.gov./pumed/18520749 